\title{
The frail world of haemodialysis patients in the COVID-19 pandemic era: a systematic scoping review
}

\author{
Gaetano Alfano ${ }^{1,2,3} \cdot$ Annachiara Ferrari ${ }^{4} \cdot$ Riccardo Magistroni $^{1,2} \cdot$ Francesco Fontana $^{2} \cdot$ Gianni Cappelli $^{1,2}$. \\ Carlo Basile ${ }^{5,6}$ (1)
}

Received: 11 May 2021 / Accepted: 24 July 2021 / Published online: 21 August 2021

(c) Italian Society of Nephrology 2021

\begin{abstract}
Background Patients undergoing in-centre haemodialysis (HD) are particularly exposed to the dire consequences of COVID19. The present systematic scoping review aims to identify the extent, range, and nature of articles related to COVID-19 and maintenance HD: it reports specifically the prevalence of the COVID-19 pandemic in the HD population, implementation of strategies for the prevention, mitigation and containment of the COVID-19 pandemic in HD centres, demographic and clinical characteristics, and outcomes of the pediatric and adult HD patients.

Methods A multi-step systematic search of the literature in Pubmed, Scopus, Ovid Medline, Embase and Web of Science, published between December 1, 2019, and January 30, 2021 was performed. Two authors separately screened the titles and abstracts of the documents and ruled out irrelevant articles. A report of the papers that met inclusion criteria was performed; then, a descriptive analysis of the characteristics of the included articles and a narrative synthesis of the results were performed.

Results The review process ended with the inclusion of 145 articles. Most of them were based on single-centre experiences, which spontaneously developed best practices. Most studies were conducted in high-income countries (69.7\%) and a part of them (9.6\%) were not in English. Prevalence of COVID-19 among dialysis patients accounted for 0\%-37.6\%. Preventive measures were reported in $54 \%$ of the included articles, with particular emphasis on education, triage, hygiene, and containment measures. Patients experienced a heterogeneous spectrum of symptoms that led $35 \%-88.2 \%$ of them to hospital admission. Median and mean hospital length of stay ranged from 8 to 28.5 and 16.2 to 22 days, respectively. Admission to intensive care units varied widely across studies (from $2.6 \%$ to $70.5 \%$ ) and was associated with high mortality (42.8\%-100\%). Overall, prognosis was poor in $0 \%-47 \%$ of the hospitalized patients.

Conclusions This systematic scoping review provides an overview of the current knowledge on the impact of COVID-19 on the frail world of HD patients. Furthermore, it may help to implement the existing strategies of COVID-19 prevention and provide a list of unmet needs (safe transport, testing, shelter). Finally, it may be a stimulus for performing systematic reviews and meta-analyses which will form the basis for evidence-based guidelines.
\end{abstract}

Carlo Basile

basile.miulli@libero.it

Gaetano Alfano

gaetano.alfano@unimore.it

Annachiara Ferrari

fannachiara@gmail.com

Riccardo Magistroni

riccardo.magistroni@unimore.it

Francesco Fontana

francesco.fontana@unimore.it

Gianni Cappelli

gianni.cappelli@unimore.it
1 Surgical, Medical and Dental Department of Morphological Sciences, Section of Nephrology, University of Modena and Reggio Emilia, Modena, Italy

2 Nephrology, Dialysis and Transplant Unit, University Hospital of Modena, Modena, Italy

3 Clinical and Experimental Medicine, University of Modena and Reggio Emilia, Modena, Italy

4 Nephrology and Dialysis Unit, AUSL Reggio Emilia-IRCCS S. Maria Nuova, Reggio Emilia, Italy

5 Division of Nephrology, Miulli General Hospital, Via Battisti 192, Acquaviva delle Fonti, 74121 Taranto, Italy

6 Associazione Nefrologica Gabriella Sebastio, Martina Franca, Italy 


\section{Graphic abstract}

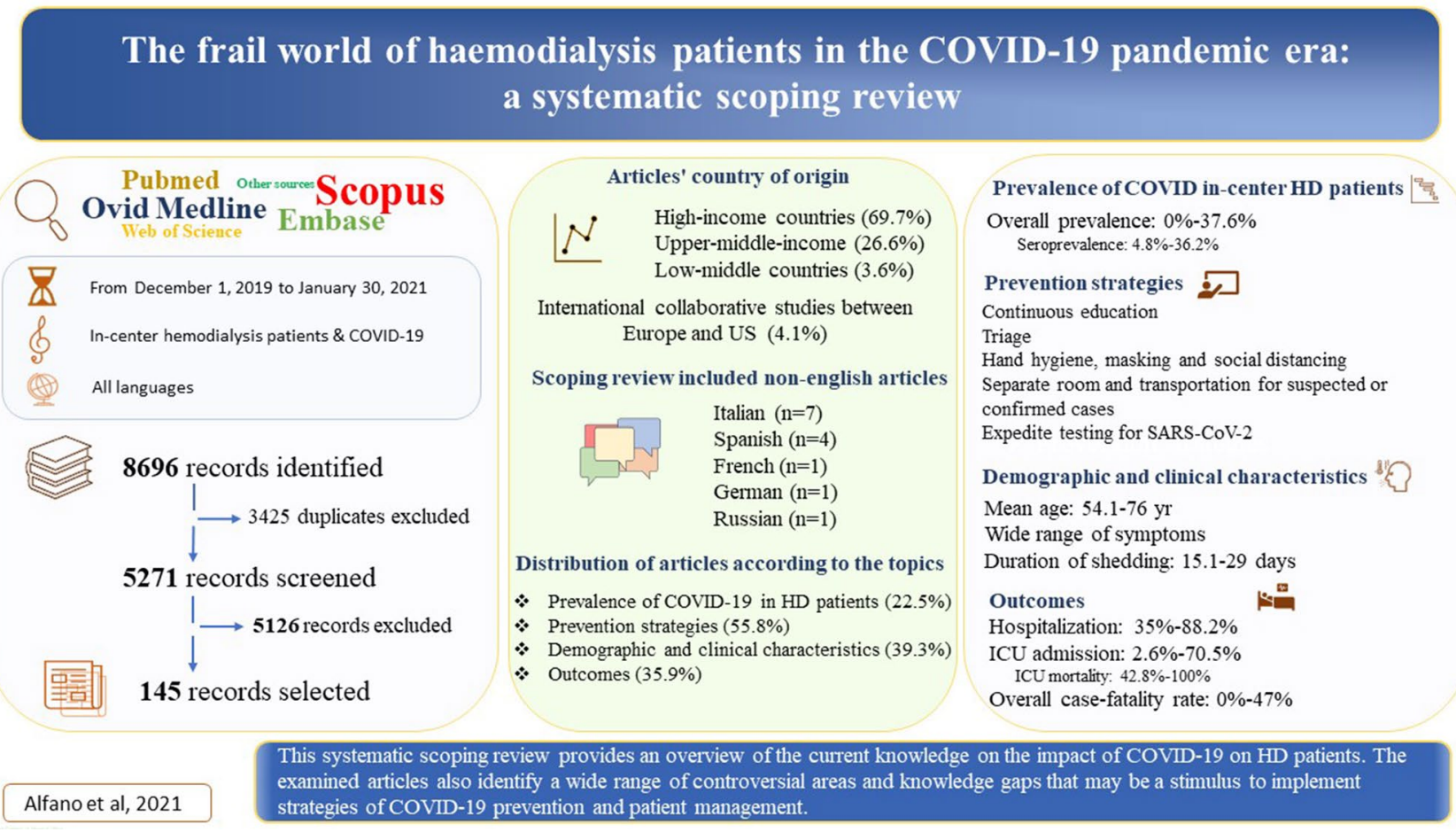

Keywords End-stage kidney disease $\cdot$ COVID-19 $\cdot$ SARS-CoV-2 $\cdot$ Haemodialysis

\section{Introduction}

Emerging evidence shows that patients with advanced chronic kidney disease (CKD) are susceptible to the detrimental effects of COVID-19 [1]. Patients on renal replacement therapy, especially haemodialysis (HD) patients, convey a higher risk of death compared to the general population [2-4]. Although age and the burden of accompanying comorbidities are associated with a poor outcome [5], dialysis condition is, per se, an independent factor for death after contracting COVID-19 [6]. Chronic maintenance dialysis is known to induce an immune system dysfunction that theoretically lessens responsiveness to SARS-CoV-2 infection. Furthermore, in-centre HD patients are more susceptible to COVID-19 because they lack the possibility to shelter at home during the outbreak. For their dependency on in-centre dialysis treatment, patients need to reach the dialysis unit thrice weekly and often travel to and from it with public or shared transport. This inevitably increases the risk of SARSCoV-2 infection [7].

On this background, the deleterious association between COVID-19 and the high mortality rate in dialysis patients urged the nephrology community to adopt appropriate infection control measures to prevent viral infection spread. These interventions, rapidly implemented into clinical practice, have shaped the local and national guidelines to mitigate the risk factors associated with SARS-CoV-2 infection. However, the lack of international consensus guidelines on patient management and aggregate data on epidemiology and outcomes of COVID-19 has in part limited the effectiveness of these measures. Furthermore, the different containment strategies related to structural problems of some dialysis units and divergent national guidelines had the disadvantage of increasing heterogeneity across studies. In order to broaden our understanding of the effects of COVID-19 on HD patients and identify gaps in the current literature, we conducted a systematic scoping review with the aim of mapping and analyzing actual evidence on the prevalence, clinical manifestations and outcomes of the pediatric and adult HD patients during COVID-19 pandemic. A secondary objective of this scoping review was to help the nephrologist to navigate into the vast literature published on the COVID-19 and offer the opportunity to focus on knowledge gaps and/or controversial areas that need further investigations. However, given the evolving situation of COVID-19 worldwide, this review should be considered a "work in progress" project. Indeed, the map of the currently available evidence will 
evolve in parallel with the full understanding of COVID19 pathogenesis in the general population as well as in patients on maintenance HD.

\section{Methods}

\section{Search strategy}

This systematic scoping review aimed to furnish an overview of the available literature on two research questions:

- Which has been the magnitude of the impact of the COVID-19 pandemic on the frail world of the HD patients?

- What strategies were implemented in the clinical practice for the prevention, mitigation and containment of the COVID-19 pandemic in HD centres?
To address this broad topic of interest, we followed published recommendations of Preferred Reporting Items for Systematic Review and Meta-Analysis Protocols (PRISMAP) checklist and the PRISMA extension for scoping reviews $[8,9]$. We also corresponded with experts in the field to sharpen search strategy and selection criteria. The review was not prospectively registered in any database of literature reviews (e.g., PROSPERO) as it was not applicable.

The search strategy was conducted after consultation with two librarians (C.P. and G.V) with expertise in the scientific literature. A literature search from December 1, 2019 to January 30, 2021 was conducted on the following 5 databases: PubMed, OVID Medline, Scopus, Embase, Web of Science and Google Scholar. Search in Cochrane Library did not furnish any results. The database results were uploaded on a reference manager software (Mendeley ${ }^{\circledR}$ ).

We performed a multi-step search strategy (Fig. 1) [10] fully reported in the Supplementary Material. After identification of the literature, all duplicates were removed
Fig. 1 Preferred reporting items for systematic reviews and meta-analyses (PRISMA) flow diagram of the study

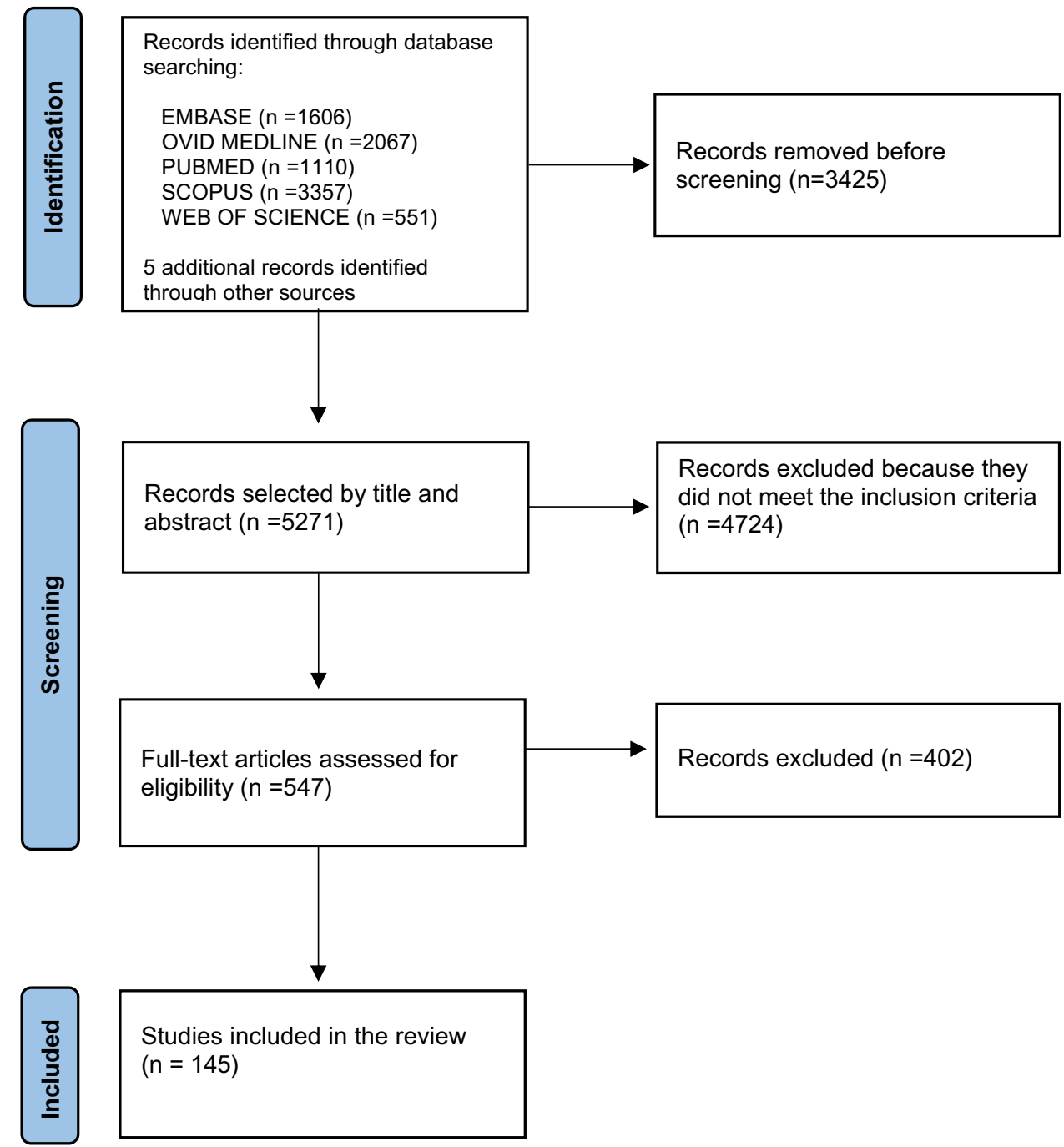


automatically. The screening of the articles consisted of two stages: eligibility of references according to inclusion and exclusion criteria and selection of the articles. Selection of the articles was independently accomplished by two reviewers (G.A and A.F.) after the screening of titles and abstracts followed by the retrieval and screening of fulltext articles. Disagreements were resolved through discussion between the two reviewers, or with the help of a third reviewer (R.M.), a researcher with 16 years of experience in the field of nephrology. Data charting from the selected studies included information on authorship, type of study, country, study population, modality of COVID-19 diagnosis, prevalence of the COVID-19 pandemic in the HD population, implementation of strategies for the prevention, mitigation and containment of the COVID-19 pandemic in HD centres, demographic and clinical characteristics, and outcomes of the pediatric and adult HD patients.

\section{Results}

Our search retrieved 8696 articles of which 5271 remained after the exclusion of duplicates (Fig. 1). After title and abstract screening, 4724 articles were further removed. The full texts of the remaining 547 articles were screened and 402 were excluded. The final review comprised 145 articles.
Most articles (69.7\%) come from high-income countries whereas the remaining articles come from upper-middleincome (26.6\%) and low-middle countries (3.6\%) (Fig. 2). Six $(4.1 \%)$ international collaborative studies were conducted in Europe and US. The review included articles that were translated into English from French (1), German (1), Italian (7), Russian (1) and Spanish (4). The arguments discussed in the review have been grouped into 4 domains: prevalence of the COVID-19 pandemic in the HD population, implementation of strategies for the prevention, mitigation and containment of the COVID-19 pandemic in HD centres, demographic and clinical characteristics, and outcomes of the COVID-19 HD patients.

\section{Prevalence of the COVID-19 pandemic in the HD population}

Prevalence of COVID-19 was reported in 22 (15.1\%) studies, including 7 letters to the editor (31.8\%). The population screened for COVID-19 consisted of 8338 patients (range 13-1542). Studies were conducted principally in China $(31.8 \%)$ and Spain $(27.2 \%)$. As detailed in Table 1S, different screening tests were used to estimate the prevalence of COVID-19. The screening was carried out using realtime polymerase chain reaction (RT-PCR) (45.5\%) [11-21], serology $(27.2 \%)$ [18, 20, 22-25], computed tomography (CT) scan (confirmed by SARS-CoV-2 RT-PCR) (13.6\%)

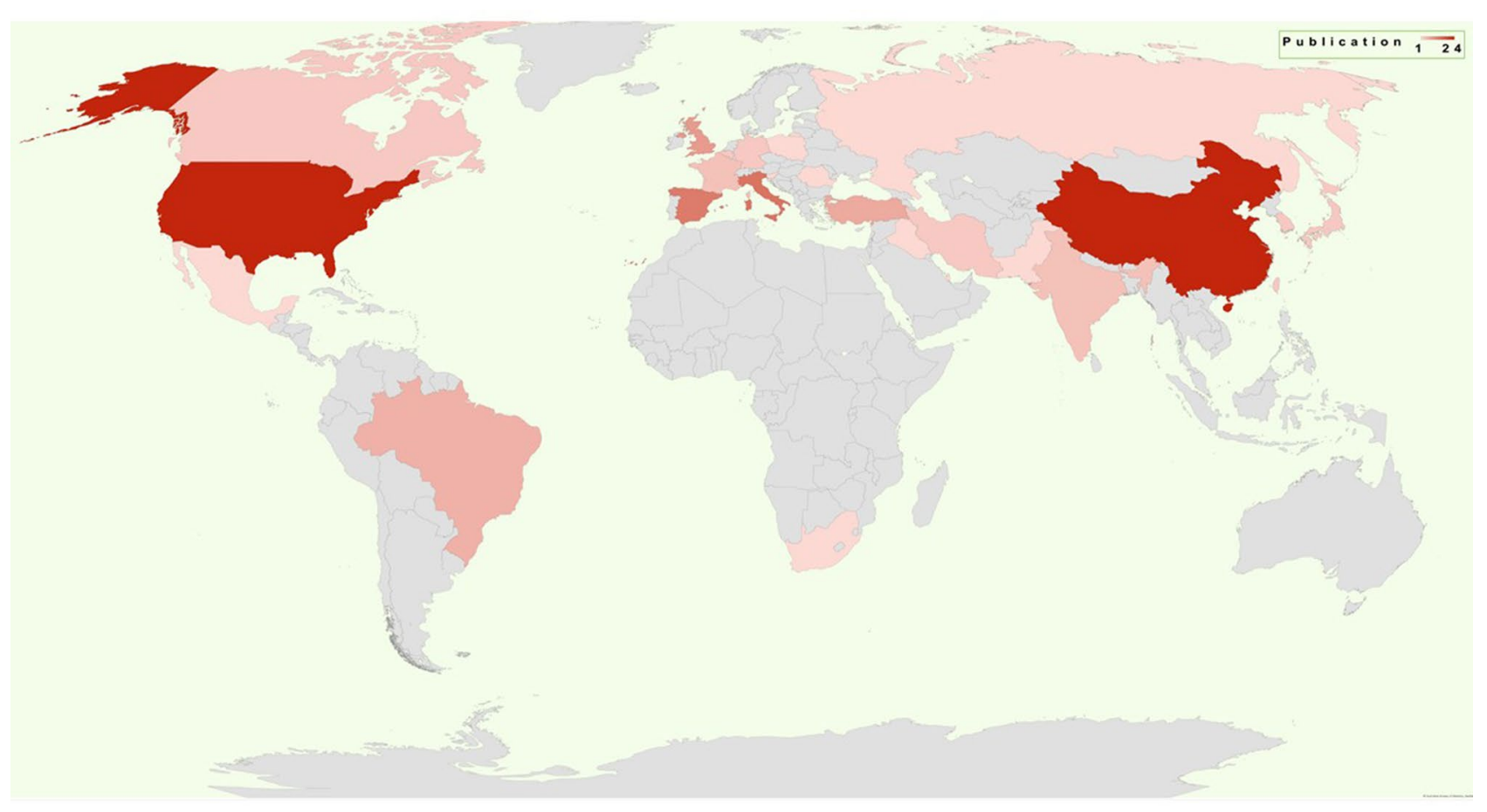

Fig. 2 World distribution of articles retrieved for the review (Singapore is not displayed on the world map but contributed with three publications) 
[26-28] and combination of PCR and serology (13.6\%) [29-31]. Considering all modalities of testing, prevalence of COVID-19 among HD patients ranged between 0 and $37.6 \%$ [11-32]. When COVID-19 was diagnosed by antibody testing, prevalence varied from 4.8 to $36.2 \%$ [23, 25]. A seroconversion of $97.5 \%$ was detected in PCR-positive patients [23], whereas it occurred in 4.4-19.0\% [20, 23] of PCR-negative patients. Prevalence of COVID-19 in pediatric patients was assessed in only two studies reporting a seroprevalence of $23-38 \%$ (Fig. 1S) [22, 24]. The results of the epidemiology studies highlighted that asymptomatic patients accounted for about one-quarter of PCR-based screening of HD population (Fig. 2S).

\section{Implementation of strategies for the prevention, mitigation and containment of the COVID-19 pandemic in HD centres}

Surveillance and appropriate management of suspected or confirmed COVID-19 patients play a key role in the prevention, mitigation and containment of the COVID-19 pandemic in HD centres. Management of in-centre patients was reported in $81(55.8 \%)$ publications, including $19(23.4 \%)$ research articles. Most of the studies came from US (23.4\%) followed by China (11.1\%) and Italy (11.1\%). A minority (5.4\%) of the articles included an international authorship.

\section{Education and recommendations}

Given the evolving situation, continuous education on COVID-19 was considered essential for HD patients [33-44]. Dialysis staff provided patients with instructions (in appropriate languages) [41, 44-48] about respiratory hygiene, coughing and sneezing etiquette [39, 43, 45-52], how to use the masks $[34,39,44,46-48,52-54]$ and how to practice self-quarantine at home and with family members after dialysis [50]. Signed posts or distribution of educational pamphlets in the patient's language were also part of the educational program on COVID-19 [12, 33, 38, 47, 50, 55, 56].

Particular emphasis was placed on hand hygiene, masking and social distancing. Handwashing [29, 33, 34, 40, 43, $57,58]$ with alcohol-based solutions or soap [41, 42, 47, $51,54,56,58-61]$ was advocated for patients presenting at triage $[12,21,38,47,54,56,62-64]$, prior to departure from the dialysis unit $[38,47,64]$ and if in contact with respiratory secretions $[33,47]$. Fistula arm was washed before starting dialysis $[16,29,60]$. In the COVID area, patients implemented personal protective equipment (PPE) including gloves throughout the dialysis session [29, 65-67].

Patients were instructed to wear a surgical mask since leaving house [38] until hospital arrival [16, 35, 38, 43, 56, $63,66,68]$ and also during the ride $[49,54,55]$. To reduce the risk of infection within facilities, the use of the mask was recommended throughout the dialysis session $[35,36,44$, $49,51,54,55,57,60,61,63,69-73]$ unless it was made of textiles[54] or was worn by someone that was incapacitated to remove it without assistance [48]. Conversely, some recommendations supported the choice to wear a mask according to the epidemiology risk in the community principally for asymptomatic patients [38].

With regard to family relationships, HD patients needed to reduced contact with other people on their non-dialysis days $[33,47,51,65,73]$. Personal contacts, especially with younger relatives $[33,47,65]$ were discouraged. A similar restriction was valid also for public, private or religious events or travels [47].

\section{Transport}

Use of individual transport to and from dialysis facilitiesinstead of public or shared transport-was proposed as a measure to prevent diffusion of COVID-19 [29, 33, 39, 40, $42,47,49,68,73]$. Drivers were instructed to comply with infection control measures [29, 33, 38, 42, 57] including sanitization of the shuttle bus between rides [29, 33]. Drivers were invited to report any patient with symptoms to the dialysis facility and vice versa [33, 44]. Hand sanitizers needed to be accessible for patients and drivers on vehicle [33] and hand hygiene was required before and after entering the vehicle [38].

Public transport for suspected and/or confirmed COVID19 patients was forbidden [29, 49-51, 53, 57, 62, 74]. In the absence of separate transportation, patients with confirmed COVID-19 were gathered in the same vehicle, providing them with a mask [38]. A possible solution for a patient who could not be provided with a separate transport was hospitalization [42].

\section{Structural changes in the dialysis units}

Different routes (including lift) for symptomatic and asymptomatic patients were designed to avoid cross-contamination among subjects [21, 29, 34, 60, 75].

Dispensers of hydro-alcoholic solutions [39, 41, 47, 50, 60] were installed in waiting rooms and, more generally, in the facility [43, 67]. Availability of tissue paper, masks $[39,50]$, easy access to PPE $[33,74]$ and a distance of at least 1-1.5 [61], 1.8-2 $\mathrm{m}$ [36, 48, 76] between patient beds needed to be ensured in the dialysis centre.

A separate room was reserved for testing $[29,38,47,67$, 74] suspected or confirmed COVID-19 patients [16, 21, 29, $33,36-38,40,43,46-48,50,52,56,57,62,68,77-79]$. Although it was not a primary prerequisite $[38,46]$, a negative air pressure room was preferable for quarantine patients $[37,47,49,80]$. In absence of a separated room, suspected 
or infected patients were courted on a separate shift [38], namely, during the last shift of the day, in a corner or at the end-of-row station $[33,35,36,38,43,44,47,48,50,52$, $53,72]$.

Cohorting suspected or confirmed COVID-19 patients together with asymptomatic subjects required droplet/contact precautions [38] and the maintenance of a distance longer than $1.8 \mathrm{~m}$ (6 feet) [44, 50, 52], $2 \mathrm{~m}[36,40,53,55$, 67] or as far as possible [36]. Another option was maintaining at least $2 \mathrm{~m}$ between patients using separating materials to provide spatial isolation $[37,38]$.

Peripheral dialysis centres, without the possibility of isolation and care of suspected or confirmed COVID-19 patients, needed to centralize patients towards referring hospitals [60].

Identifying toilet for suspected or infected cases [40], and maintaining good air conditioning and ventilation of dialysis rooms was suggested as preventive measures $[36,47,51$, $53,67,79]$.

\section{Functional changes in the routine dialysis care}

Patients were assigned to specific dialysis shifts [36, 49, 71] and patterns of patient flow were controlled by dialysis staff during the shift changes $[49,71]$. Screening of the patients was required before shifting them to another unit [56].

Patients from different long-term care facilities or from other units were not cohorted together unless full droplet/ contact precautions were respected [38]. Cohorting symptomatic patients with probable or suspected COVID-19 was forbidden [38, 47].

Among the series of containment measures patients had to enter the locker room one by one and left all their clothes inside the locker [29] or changing clothes and shoes before entry into the dialysis room [61].

Visitors were limited [44] or not allowed in the dialysis facilities [12, 21, 33, 39], even though a more permissive recommendation allowed the presence of visitors only if they facilitated the dialysis treatment of asymptomatic patients [38].

Number of dialysis per day was increased to reduce the number of patients per shift as well as in the waiting room [74]. Frequency of dialysis sessions was not shortened or paused to leave unaffected dialysis quality [36]. However, in a resource-constrained environment, a strategy could be taken into account shortening dialysis treatment time to $3 \mathrm{~h}$ in all stable patients [29] or reducing a three times weekly HD program to twice-weekly dialysis [81]. The latter solution should be considered provisional and be reserved for patients with preserved residual kidney function, minimal inter-dialytic weight gain and without hyperkalaemia or severe comorbidities [38]. For new dialysis patients, incremental twice-weekly dialysis could be taken into account to limit their time in the dialysis units [82].

The frequency of routine bloodwork and access flow measurement for stable patients was reduced to no more than 6 weeks unless clinically indicated [38]. Teleconsultation was implemented to decrease medical contact with patients [83].

\section{Testing for COVID-19}

Dialysis patients should be prioritized to have expeditious access to testing for COVID-19 [38]. Criteria for performing screening tests varied among studies. Two recommendations were released: universal screening for every dialysis patient [84] or reserving testing only for symptomatic patients [47, $48,56,85,86]$. However, despite the consistent implementation of SARS-CoV-2 testing, diagnosis of COVID-19 remained challenging in some dialysis units [87].

It was recommended to repeat a nasopharyngeal swab in case of a negative test for COVID-19 and a high clinical suspicion $[38,79,80]$. Infectious disease specialists consultation was required if more than 2 tests for a single patient resulted negative [38].

One study reported that CT scan once every 2 weeks was considered helpful to recognize and isolate patients as early as possible in the incubation period [80]. Conversely, other authors asserted that CT scan [38] as well as serology [48, $68,79]$ (in the acute phase) were inappropriate for the diagnosis of COVID-19.

\section{Pre-triage and waiting area}

According to staff availability, dialysis staff phoned all patients before each dialysis shift to determine whether they had COVID-19 symptoms [17, 33, 45, 88]. Another strategy consisted of informing the facility of suspicious symptoms or contacts with COVID- 19 subjects [38, 42-44, 49-53, 55, $57,63,65,67,72,86,88,89]$ or in case of contact with COVID-19 patients [70].

Patients and transport companies were advised for progressive arrival and departure times to avoid overcrowded areas [29], and medically stable patients were suggested to wait outside the facility or in their vehicles $[29,38,44,47$, $48,52,67,90]$.

If the patients would wait in a communal area, sits needed to be separated by at least $1,[72] 1.5[42,49,62]$ or about $2 \mathrm{~m}$ (6 feet) apart from each other [29, 33, 38, 42-45, 47-49].

Patients with confirmed COVID-19 were not allowed to wait in the common area $[38,48]$, unless (for special needs) they wore a mask and maintained $>2 \mathrm{~m}$ distance from others [38]. 


\section{Triage}

A pre-dialysis triage was based on the assessment of symptoms or signs suggestive for COVID-19 [29, 36-38, 41, 43-45, 47, 48, 50, 51, 58, 62, 66, 72, 79, 80, 86, 89, 91-93].

A questionnaire was provided regarding symptoms, exposure, contact and travel history for all the patients at every shift of dialysis [17, 33, 38, 52, 73]. This could be reserved even to visitors if they were allowed [38]. Atypical symptoms, including change from previous well-being and altered neurological status were considered suspect in the elderly and immune-compromised patients [38].

Body temperature was measured to all people prior entry to the dialysis centre $[12,29,38,41,47,53,58,61,64$, $66,68-70,73,80,92-95]$ using digital $[12,93]$ or infrared thermal devices [88].

An alert temperature was set at $\geq 37{ }^{\circ} \mathrm{C}[90], 37.3{ }^{\circ} \mathrm{C}$, $[35,38,96] \geq 37.5^{\circ} \mathrm{C}[29,34,66,72,93], 37.8^{\circ} \mathrm{C}[48$, $90], 38{ }^{\circ} \mathrm{C}[49,89,97]$ in different studies. A re-check of temperature with different types of thermometer was practiced [93]. After triage, some recommendations suggested a double-check of temperature and respiratory symptoms in the waiting room [96]. In some places patient's temperature measurement was performed before getting into shuttle bus headed to HD unit [97] or body temperature check was combined with a QR code (dowloaded on the mobile phone) reporting the epidemiological risk of the patient [95].

\section{During the dialysis session}

Eating was not allowed during the dialysis session [16, 29, $36,39,66]$ to minimize time without mask [42, 90]. Special indications were released for diabetic patients after testing blood glucose [29]. If the patient manifested dyspnoea or any other clinical suspicious symptoms (temperature $\geq 37.5^{\circ} \mathrm{C}$ ) [97], HD session had to be stopped and the patient moved to a separate area for SARS-CoV-2 screening [16].

\section{Screening and management of patients under investigation}

According to local rules, the patients suspected of COVID19 were sent to: (1) emergency room; [62, 66, 67] (2) hospital (e.g., COVID-19 referral hospital); [80] (3) dedicated isolated area in the dialysis ward [40, 66, 67]; (4) back home [62] or postponing HD session till the availability of the nasopharyngeal swab result $[62,74]$. However, according to national recommendation, even asymptomatic patients could be hospitalized to control the spread of the infection [53].

From a clinical standpoint, physical examination and workup were suggested before dialysis $[60,66,90]$. Beyond SARS-CoV-2 PCR nasopharyngeal swab, [16, 62] examinations included lab blood tests, [16] arterial blood gas analysis, oxygen saturation, measurement of body weight, and chest X-rays [62]. Assessment of the patient's fluid status was essential to plan the next dialysis session [89].

Patients under investigation with negative tests were deescalated back to their dialysis unit unless they remained symptomatic. In such patients, the plan was to continue cohort dialysis until the second swab came back as negative [57].

Recommendations for asymptomatic contacts consisted of a screening tests for COVID-19 and the referral to the HD cohort isolation adopting contact and droplet precautions $[34,48,86]$. In this setting, cohort isolation was discontinued after a negative result of nasopharyngeal swab on the thirteenth day after contact [34].

\section{Management of the confirmed COVID-19 HD patients}

According to the national guidelines, an outbreak of COVID-19 in dialysis units could be notified to the local public health department [38, 46, 48]. Confirmed COVID19 patients were preferably managed in an outpatient setting $[49,74]$ if they were stable and there was the possibility to maintain home isolation and use dedicated transport. This strategy allowed to minimize the need for hospitalization beds [49].

High-efficiency dialyzers were used since many patients were considered in high catabolic states [98]. Heparin-free dialysis was avoided to reduce the need for frequent circuit flushing [92] and the risk of clotting [42]. One study underlined that despite some thromboembolic events (dialyzer clotting, arteriovenous fistula thrombosis) dose of heparin was not increased for all COVID-19 patients [21].

When the HD patient was admitted to a non-ICU ward, portable dialysis machines (including reverse osmosis machines) were used to keep COVID-19 patients in their rooms $[36,66,81]$. If the patient was being followed-up in the ICU, intermittent or continuous renal replacement therapy could be performed at the bedside [36]. Dialysis machines used for infected patients were generally restricted in COVID-19 areas [49, 62, 99].

\section{Discontinuation of isolation}

Isolation must have continued until the patient became asymptomatic, for a minimum of 14 days and until 2 negative tests were separated by at least $24 \mathrm{~h}[38,42]$. Another recommendation reported that asymptomatic patients could only be de-isolated after two consecutively negative results with a $24-[34,58,62,80]$ or 48-h [42] interval regardless of the time elapsed from the diagnosis. However, if symptoms persisted, the patient continued HD treatment in an isolated room, even with a twice negative test [34]. Duration of isolation could be longer than 14 days for immune-compromised patients $[38,100]$; therefore, a test-based strategy was 
suggested to avoid the risk of SARS-CoV-2 spreading [86]. Consultation with health authorities or local infectious disease experts on a case-by-case basis was suggested [38,47].

\section{Surgical operations}

Surgical revision of malfunctioning vascular access [101] or the placement of vascular access remained an essential life-saving procedure [33, 44, 50, 101-104]. A local rule supposed to postpone the creation of arteriovenous fistulae for patients within six months of requiring HD [57].

Before vascular access surgery, patients underwent COVID-19 screening [47, 67, 105]. Operations on patients with confirmed or suspected COVID-19 infection were carried out in a designated room [47] if postponing the procedure was not advisable [101].

\section{Disinfection}

Dialysis stations and chairs were disinfected per protocol (using active product on SARS-CoV-2) [12, 38, 44, 46, $48-52,66]$ including handrails on scales, waiting room seats, doorknobs and elevator buttons [46, 74]. Disinfection of hospital linens required soap and high temperature [65].

Ventilation [36, 40, 75] and terminal disinfection of the room including equipment and supplies was advised between two dialysis shifts [35, 38, 67, 75, 78, 94]. One percent diluted bleach (sodium hypochlorite) was used for floor and surface disinfection and 10\% diluted bleach or $70 \%$ alcohol for areas contaminated with patient secretions [53, $56,72,73,75]$; instead, nebulizing hydrogen peroxide was used for room decontamination [12].

\section{Pediatric patients on HD}

Four articles reported the recommendations for pediatric patients on dialysis. Education about COVID-19 including hand, respiratory hygiene and use of PPE was provided for patients and caregivers [76, 106, 107]. Caregivers were instructed to advise the dialysis unit of Covid-19 symptoms before entry [76]. Private transportation [59, 106] or transportation provided by health authorities were suggested [106]. Children were accompanied by only one caregiver, preferably always the same $[76,106]$.

It was recommended to wear a mask $[59,76,106,107]$ (unless $<2$ years old) [48], wash hands with alcohol-based hand rub [59, 76, 106] and maintain a social distance between other patients of at least $1 \mathrm{~m}$. [59, 76] Screening of body temperature $[59,107]$ and respiratory symptoms [107] was required for patients and families before entry into dialysis facilities [76].

Dialysis beds needed to be spaced at a minimum distance of 1-2 m apart [76, 106, 107]; if these conditions could not be met, curtains were used to separate patients [107]. Unnecessary talking or eating was avoided during dialysis [106, 107].

Transfer of patients to different dialysis units was reduced as a control measure [106].

COVID-19 patients or suspected patients were dialyzed in a dedicated room at the last shift or with the same dialysis machine [59, 106, 107]. Patients with a COVID-19 positive caregiver performed dialysis in an isolated room [76, 107].

For all patients, dialysis was not reduced or shortened [59]. Suspected or confirmed COVID-19 patients were transferred to designated COVID-19 HD units if there was no space and/or a dedicated workforce [76].

Disinfection measures were applied between each shift using $1 \%$ bleach solution or $70 \%$ alcohol-based solution [76]. The dialysis machine was wiped with $70 \%$ ethyl alcohol or $0.05 \%$ chlorine solution [106].

\section{Perspective}

Only one report emphasized the need to construct appropriate numbers of isolation rooms, adequate spacing between dialysis beds and space in the waiting room for future dialysis units. [38]

\section{Demographic and clinical characteristics of the confirmed COVID-19 HD patients}

Clinical characteristics of in-centre HD patients with COVID-19 have been detailed in 57 (39.3\%) studies including 7376 patients (range 1 to 2336) (Table 2S). The majority of studies were conducted in China (21\%) followed by Spain (14\%) and UK (10.5\%); $1.7 \%$ of the articles included an international authorship.

Age of confirmed COVID-19 patients on HD was largely heterogeneous since principally tends to reflect national policy of access to dialysis treatment. Median and mean age of this large cohort of patients ranged between 48 and 79.5 years $[11,15,17,21,23,61,82,94,108-122]$ and 54.1-76 years, $[6,19,25,31,32,69,93,123-135]$ respectively. The percentage of male was $37.5 \%-100 \%$ of the examined population $[11,13,15,17,19,21,23,25,31,32,69$, 82, 94, 108-131, 133-138].

In order to investigate the clinical manifestations of COVID-19 in HD patients, we collected information on COVID-19-related symptoms. Observation of the data led to the conclusion that COVID-19 HD patients showed a wide range of symptoms that reflected the pleiotropic manifestations of the infection. The worsening of symptoms led to the hospitalization in $35 \%-88.2 \%$ of cases. The prevalence of the main COVID-19-related symptoms is shown in Table 1. 
Table 1 Prevalence of COVID-19-related symptoms in HD patients

\begin{tabular}{|c|c|}
\hline Symptoms/signs & Prevalence \\
\hline \multicolumn{2}{|l|}{ Adult population } \\
\hline Fever & $\begin{array}{l}9-100 \%[6,11,13,15-17,21,69,93,94,108-110,112,114,116,119-125,127,130 \text {, } \\
\quad 133,135,143]\end{array}$ \\
\hline Cough & $\begin{array}{l}7.1-83.9 \%[6,13,15-17,21,27,69,108-112,114,116,119-125,130,132,133,135 \text {, } \\
138]\end{array}$ \\
\hline Myalgia/fatigue & $2.9-63 \%[6,11,15,21,27,69,108,110-112,114,119-125,130,132,135]$ \\
\hline Anorexia & $9.3-57 \%[27,110,112,114,121]$ \\
\hline Dyspnea/gasping & $\begin{array}{l}0-56 \%[6,11,15-17,21,27,69,93,108-112,114,119-122,125,127,130,132,133 \text {, } \\
138]\end{array}$ \\
\hline Nausea/vomit & $4.7-43.6 \%[6,13,69,110,112,121,122,143]$ \\
\hline Gastrointestinal/diarrhea & $0-40 \%[6,11,15,16,21,69,93,108-111,114,116,119-125,132,133,135,138]$ \\
\hline Expectoration & $21.4-33 \%[69,121,132]$ \\
\hline Anosmia/dysgeusia & $4-21.6 \%[113,116,133]$ \\
\hline Sore throat & $0-20 \%[6,11,16,17,21,27,69,108,111,112,114,132]$ \\
\hline Headache & $6.25-8.1 \%[6,111,114,121]$ \\
\hline Altered mental status & $5 \%[138]$ \\
\hline Ageusia & $3-13 \%[21,116]$ \\
\hline Chest pain & $2.3-6.5 \%[21,124]$ \\
\hline Conjunctival congestion & $7.6 \%[109]$ \\
\hline Dizziness & $14 \%[121]$ \\
\hline Rhinorrhea/nasal congestion & $0 \%-14.3 \%[109,112,132]$ \\
\hline Abdominal pain & $5.2 \%[135]$ \\
\hline Ischemic stroke & $20 \%[146]$ \\
\hline Lymphocytopenia & $50-100 \%[15-17,21,25,93,110,111,118,130]$ \\
\hline Weight loss* & $40-100 \%[21,143]$ \\
\hline Chest X-ray abnormalities ${ }^{\#}$ & $46-81 \%[6,11,108,123,129,135,136]$ \\
\hline Computed tomography abnormalities ${ }^{\#}$ & $27.5-100 \%[6,15,19,25,111,112,114,120,121,125,132,133]$ \\
\hline \multicolumn{2}{|l|}{ ICU Pediatric population } \\
\hline $\begin{array}{l}\text { Fever, fatigue, poor appetite, headache and lymphope- } \\
\text { nia at lab tests } \\
\text { Chest X-ray negative for COVID-19 lesions }\end{array}$ & Case-report [141] \\
\hline Fever, body aches, cough, fatigue and nasal congestion & Case-series (one out of three patients was symptomatic) [149] \\
\hline
\end{tabular}

*Mean weight loss of $2.4 \mathrm{~kg}[21,154]$

"Imaging abnormalities refer to COVID-19-related lesions

\section{Shedding}

Data on RNA shedding after COVID-19 diagnosis have been reported in 6 articles, including one case report. Nasal shedding of SARS-CoV-2 was detected in $41 \%$ of patients by day 15 following the initial positive swab [100]. On average shedding of viral particles lasted 15.1-29 days in infected patients on HD [135, 139]. Two studies reported that HD patients tested positive for SARS-CoV-2 RNA on repeated testing despite being negative on two prior consecutive nasopharyngeal swabs $[138,140]$. Prolonged viral RNA shedding has been reported until 79 days in an adult HD patient [140] and 28 days in a pediatric patient [141]. Only one anecdotal case of reinfection has been reported in a dialysis patient [142].

\section{Diagnosis}

In research articles reporting clinical manifestation and outcome of COVID-19 patients (78[54.4\%]) the diagnosis of SARS-CoV-2 infection relied principally on RT-PCR (52[63.4\%]) [11-20, 32, 61, 62, 69, 93, 94, 100, 108-111, $113,115-124,126,129,132,134,135,138-151]$, serology $(4[6.3 \%])[18,20,22-24,86,99]$, RT-PCR and serological assay $(5[6.6 \%])[29-31,85,127,152]$ or a combination of diagnostic tests including clinical evaluation [6, $13,19,21,112,114,125,128,130,131,133,136,137$, $153,154]$. 


\section{Outcomes of the confirmed COVID-19 HD patients}

Outcome of patients on in-centre HD was evaluated on 52 (35.9\%) articles including 12,365 patients (range 11-3160) COVID-19 patients (Table 3S). Studies come principally from China (15.3\%), Italy (15.3\%) and Spain (11.5\%); $3.8 \%$ of the studies included European authorship. Table 2 describes the timing of the main events occurring in the COVID-19 HD patients. All outcome measures were influenced by the sample size, the age of patients, length of follow-up and policy of healthcare delivery. Excluding studies reporting outcome of patient admitted to hospital as a preventive measure and regardless of symptoms, we found that hospitalization of HD patients varied from 35 to $88.2 \%$ $[11-13,17,21,32,62,82,93,109,114,116,118,120,127$, $129,133,136-138,144,145,150,154]$. with a percentage of patients requiring ICU admission of 2.6-70.5\% [6, 13, 17, $21,32,62,109,114,116,118,119,121,125,126,129-134$, $136,138,143,154]$. A nonlinear correlation between the rate of hospitalization and ICU admission was noticed (Fig. 3S). Case-fatality rate of $\mathrm{HD}$ patients was heterogeneus, ranging from 0 to $47 \%$ [11-13, 15, 17, 19, 21, 32, 62, 82, 93, 108, $109,112-121,123-138,143-145,147,148,150,152,154]$ and, as expected, outcome of patients who were admitted to ICU was poor with a mortality accounting for $42.8-100 \%$ of cases $[13,21,82,109,114,119,125,126,129,130,154]$.

\section{Discussion}

Systematic scoping reviews are useful for examining emerging evidence when it is still unclear what other, more specific questions can be posed and valuably addressed by a more precise systematic review [8]. This is actually the case of COVID-19 pandemic. This systematic scoping review provides a synopsis of articles relating to COVID-19 and maintenance HD patients published in the time frame December 1, 2019-January 30, 2021. The areas investigated and analyzed by this scoping review range from the epidemiology to outcome and from clinical presentation to management of in-centre HD patients with suspected or confirmed COVID-19. The main results of this study underline a worldwide broad-based consensus for public health and clinical practice in the caring of HD patients (Table 3), a subset of the population severely affected by COVID-19. The nature of a semi-closed community has probably enhanced the rapid spread of the infection within HD facilities.Except for the Canary Island where zero cases were found after a dialysis-wide universal screening [31], about $15 \%$ of the screened HD population contracted the infection (Fig. 1S). Spread of COVID-19 was global and showed a highly heterogeneous distribution, changing significantly across the cities in the same country (China, Spain). A speculative explanation of this variable disease spreading pattern suggests that COVID19 pandemic manifested with local outbreaks rather than reflecting national trends [155].

As already said, the results of the epidemiology studies highlighted that asymptomatic patients accounted for about one-quarter of PCR-based screening of HD population (Fig. 2S). The asymptomatic course of COVID-19, albeit favourable for the infected individuals, poses a threat for other patients, health workers as well as caregivers and drivers. Owing to the fact that COVID-19 can spread from asymptomatic carriers, surveillance and appropriate management of suspected or confirmed COVID-19 patients play a key role in the prevention of the infection. On this issue, a large amount of literature was published by the countries mostly hard-hit by the disease, namely, US, China, Italy, Brazil and UK [156].

Table 2 Timing of events in COVID-19 HD patients

\begin{tabular}{|c|c|c|}
\hline Timing & Days & Statistical measure \\
\hline Time elapsed from symptoms to diagnosis & $\begin{array}{l}1.5-8[11,94,115,120,132-134,157] \\
2.6-2.9[133,134]\end{array}$ & $\begin{array}{l}\text { (Median) } \\
\text { (Mean) }\end{array}$ \\
\hline Time elapsed from symptoms to hospitalization & $\begin{array}{l}2-9[11,110,122,124,157] \\
3.0-3.5[6,133]\end{array}$ & $\begin{array}{l}\text { (Median) } \\
\text { (Mean) }\end{array}$ \\
\hline Length of hospital stay & $\begin{array}{l}8-25.5[11,15,21,82,109,110,115,119,120,122, \\
\quad 124,130,132,153,157] \\
16.2-22[129,131,133]\end{array}$ & $\begin{array}{l}\text { (Median) } \\
\text { (Mean) }\end{array}$ \\
\hline Length of ICU stay & $\begin{array}{l}13-15[21,119,130] \\
6-19[131,133,134]\end{array}$ & $\begin{array}{l}\text { (Median) } \\
\text { (Mean) }\end{array}$ \\
\hline Time elapsed from diagnosis to death & $\begin{array}{l}5-31.5[15,110,139] \\
8[62]\end{array}$ & $\begin{array}{l}\text { (Median) } \\
\text { (Mean) }\end{array}$ \\
\hline Time elapsed from symptoms to death & $\begin{array}{l}7-17[11,21,109,119,124,157] \\
14-16[134]\end{array}$ & $\begin{array}{l}\text { (Median) } \\
\text { (Mean) }\end{array}$ \\
\hline Time elapsed from hospital admission to death & $\begin{array}{l}6-14[11,109,119,124,153] \\
12.3[131]\end{array}$ & $\begin{array}{l}\text { (Median) } \\
\text { (Mean) }\end{array}$ \\
\hline
\end{tabular}


Table 3 Areas of consensus and research bias of the selected studies

\begin{tabular}{|c|c|c|}
\hline Area & Consensus & Research bias/study limitation \\
\hline $\begin{array}{l}\text { Epidemiology of COVID- } \\
19 \text { within HD centers }\end{array}$ & $\begin{array}{l}\text { Variability in the prevalence rate of COVID-19 among } \\
\text { regions or countries } \\
\text { Screening of contacts and suspected COVID-19 cases } \\
\text { reduces the spread of the virus within the dialysis } \\
\text { center }\end{array}$ & $\begin{array}{l}\text { Prevalence of COVID- } 19 \text { influenced by the country's } \\
\text { exposure to the pandemic risk and timing of the screen- } \\
\text { ing } \\
\text { Seroprevalence can be biased by the rate of seroconver- } \\
\text { sion and antibody waning } \\
\text { Use of different diagnostic tests }\end{array}$ \\
\hline Management of HD patients & $\begin{array}{l}\text { Continuous education of patients is a priority within } \\
\text { HD centers } \\
\text { Triage, hand hygiene, masking and social distanc- } \\
\text { ing are the cornerstone of COVID-19 containment } \\
\text { measure } \\
\text { Expedited testing for COVID-19 } \\
\text { Separate transportation is required for suspected or } \\
\text { confirmed COVID-19 patients } \\
\text { An isolation room is required for testing and dialyzing } \\
\text { suspected or confirmed COVID-19 } \\
\text { Higher workload to dialyze COVID-19 HD patients in } \\
\text { other rooms } \\
\text { Time without mask (drinking and eating) was mini- } \\
\text { mized }\end{array}$ & $\begin{array}{l}\text { Recommendations are principally based on experts' } \\
\text { opinion } \\
\text { Lack of standardized management protocols to contain } \\
\text { diffusion within dialysis centers } \\
\text { Inadequate supply of PPE and molecular tests for } \\
\text { COVID-19 } \\
\text { Shortage of disposable HD material and } \\
\text { reverse osmosis machines } \\
\text { No consensus on the minimum distance between patients } \\
\text { in the waiting room and dialysis room, threshold body } \\
\text { temperature and device to measure body temperature }\end{array}$ \\
\hline $\begin{array}{l}\text { Demographic and clinical } \\
\text { characteristics of HD } \\
\text { patients }\end{array}$ & $\begin{array}{l}\text { Age of COVID-19 patients is heterogeneous } \\
\text { Variability in COVID-19 symptoms among HD } \\
\text { patients } \\
\text { Prolonged shedding in COVID-19 patients }\end{array}$ & $\begin{array}{l}\text { Age of incident HD patients varies among countries } \\
\text { Diagnosis of COVID-19 based on symptoms or chest } \\
\text { imaging }\end{array}$ \\
\hline Outcome & $\begin{array}{l}\text { Wide variability in the hospitalization, ICU access and } \\
\text { case-fatality rate }\end{array}$ & $\begin{array}{l}\text { Hospitalization rate is influenced by national policy on } \\
\text { the hospitalization of COVID- } 19 \text { patients } \\
\text { Mortality is influenced by bed capacity of the referring } \\
\text { hospital } \\
\text { Criteria for ICU access varies among countries }\end{array}$ \\
\hline
\end{tabular}

HD denotes hemodialysis; ICU, intensive care unit; PPE, personal protective equipment

Most of the current recommendations on the protection and control measures of HD patients derived from national guidelines, rapidly adapted to the dialysis setting to prevent the spread in the dialysis units. The analysis of the existing literature reported a common agreement on the cornerstones of the management of these patients. The principal clinical management decisions for apparently healthy individuals included education, patient collaboration (e.g., timely communication of information on contacts or variation of the clinical status), hygiene (e.g., handwashing), use of PPE (e.g., mask), social distancing and screening (e.g., triage, testing). For suspected or confirmed COVID-19 patients, the core principle of the management was based essentially on the maintenance of isolation from other patients. There was indeed a consensus to dedicate an isolated room (if any) for suspected or confirmed COVID-19 patients until the resolution of the infection. However, the map of the knowledge has brought to the light some divergences on the assessment of patients that may reflect the inter-country differences in resource availability, healthcare delivery (private or public), and the possibilities to isolate efficiently patients in their facility (hospital-based or satellite dialysis unit). For instance, a different approach has been proposed for the diagnostic pathway of SARS-CoV-2 infection. Although a routine universal screening provides an optimal and effective control measure, many authors suggested performing RT-PCR nasopharyngeal swab only in symptomatic patients. This solution, less time-consuming and more cost-effective than routine RT-PCR nasopharyngeal swab, has the main drawback of leaving undetected asymptomatic or pre-symptomatic patients.

Other differences in patient management concerned threshold of body temperature at triage, modality of COVID19 screening, distance between patients and timing of patient de-isolation. Whereas the former two issues are of easy resolution, discontinuing transmission-based precautions for HD patients relies on more complex underpinnings. The immune-suppressed HD patients may shed the virus longer than previously recognized [139]. Given the evolving recommendations on the criteria for discontinuing isolation [157, 158], may be prudential to consider HD patients as immunocompromised and await the resolution of nasal shedding before de-isolating these patients.

The outcome of the patients was heterogeneous and showed a case-fatality rate that in some cases was up to $47 \%$ [93]. Similar to the general population, exceptional higher 
mortality was found in ICU, especially if the patients underwent mechanical ventilation [159]. As already said, a nonlinear correlation between the rate of hospitalization and ICU admission was noticed (Fig. 3S) and probably underscores a low ICU utilization among hospitalized HD patients. The causes of this event remain unanswered in the review. A lack of resource availability or a rapid worsening of clinical conditions in patients with multiple comorbidities probably discouraged from intensification of cures.

This review highlights the lack of information coming from low-income countries. Limited access to essential health services and SARS-CoV-2 testing probably justify poor reporting from these countries. A further alarming problem is that COVID-19 pandemic has disproportionately affected marginalized populations including patients with CKD [160, 161]. A study conducted across the US reported high seroprevalence of COVID-19 in younger patients, and patients living in poor and minority neighborhoods [162, 163]. Considering COVID-19 could have even more dire consequences in developing countries, the paucity of data must not falsely reassure on the absence of human basic needs in these patients.

This review has some limitations. During the COVID-19 pandemic, a consistent part (about one-third) of the published literature was based on opinion papers and small case series. To generalize the message of our review we have excluded from the research abstracts, posters or conference papers. Case reports or studies with a small sample size were selectively considered in case of a shortage of evidence. Conversely, we included (when present) knowledge on pediatric HD patients. An enormous gap concerning principally the clinical course of the disease remains for this subset of the dialysis population. The milder disease course would justify the paucity of information. No data have been reported on home-dialysis patients because they carry a different profile of risk than in-centre dialysis patients.

In conclusion, this systematic scoping review provides an overview of the current knowledge on the impact of COVID19 on the frail world of HD patients. It underscores the need for extensive sharing of information between centres and within the healthcare community. A surrogate outcome of this review was the identification of knowledge gaps and areas for future research (Table 4), with the long-term goal of implementing the existing strategies of COVID-19 prevention and providing a list of unmet clinical needs (safe transport, testing, shelter) for this vulnerable group of patients. Finally, the mapping of information often by sparse and fragmented literature should be a stimulus for performing systematic reviews and meta-analyses which will form the basis for evidence-based guidelines.

Supplementary Information The online version contains supplementary material available at https://doi.org/10.1007/s40620-021-01136-5.

Acknowledgements We thank Carmela Palazzi and Giulia Valentini for their support in the search strategy of the literature.

Funding No funding agency granted the present study.

\section{Declarations}

Conflict of interest The authors have no conflicts of interest related to this manuscript.
Table 4 Controversies, knowledge gaps and areas for future research in the management of hemodialysis patients during COVID-19 pandemic \begin{tabular}{l}
\hline Definition of asymptomatic, paucisymptomatic and symptomatic COVID-19 patients \\
\hline Sensitivity and specificity of the available diagnostic tests (molecular, antigen, serologic) \\
Regulations concerning the containment measures on public transport \\
Standardization of the triage process \\
Minimum distance to prevent the spread of COVID-19 within HD center \\
Modality and timing of screening of COVID-19 in asymptomatic HD patients \\
Examinations required in HD patients with a new diagnosis of COVID-19 \\
Role of preventive hospitalization in asymptomatic COVID-19 patients \\
Use of PPE during COVID-19 pandemic in infected and non-infected patients \\
Regulations concerning eating and drinking and presence of visitors during dialysis treatment \\
Criteria for discontinuation of isolation in COVID-19 patients \\
Use of dedicated dialysis machine/room/pathway for COVID-19 patients \\
Effects of ventilation on the spread of COVID-19 within the HD center \\
Prognostic factors for severity and mortality of COVID-19 patients \\
Anticoagulation for hemodialysis in COVID-19 patients \\
Dialytic dose in COVID-19 patients \\
Priority-setting for arteriovenous fistula creation \\
Risk of reinfection in HD patients \\
Defining cleaning and disinfection protocol of room and tools
\end{tabular} 
Ethical standard All procedures performed in studies involving human participants were in accordance with the ethical standards of the institutional research committee and with the 1964 Helsinki declaration and its later amendments or comparable ethical standards.

Research involving human participants or animals This article does not contain any studies with animals performed by any of the authors.

Informed consent Informed consent is not required for this type of studies.

\section{References}

1. Williamson EJ, Walker AJ, Bhaskaran K et al (2020) Factors associated with COVID-19-related death using OpenSAFELY. Nature 584:430-436. https://doi.org/10.1038/s41586-020-2521-4

2. Valeri AM, Robbins-Juarez SY, Stevens JS et al (2020) Presentation and outcomes of patients with ESKD and COVID-19. J Am Soc Nephrol 31:1409-1415. https://doi.org/10.1681/ASN.20200 40470

3. Couchoud C, Bayer F, Ayav C et al (2020) Low incidence of SARS-CoV-2, risk factors of mortality and the course of illness in the French national cohort of dialysis patients. Kidney Int 98:1519-1529. https://doi.org/10.1016/j.kint.2020.07.042

4. Fontana F, Giaroni F, Frisina M et al (2020) SARS-CoV-2 infection in dialysis patients in northern Italy: a single-centre experience. Clin Kidney J 13:334-339. https://doi.org/10.1093/ckj/ sfaa084

5. Hsu CM, Weiner DE, Aweh G et al (2021) COVID-19 infection among us dialysis patients: risk factors and outcomes from a national dialysis provider. Am J Kidney Dis. https://doi.org/10. 1053/j.ajkd.2021.01.003

6. Hilbrands LB, Duivenvoorden R, Vart P et al (2020) COVID19-related mortality in kidney transplant and dialysis patients: Results of the ERACODA collaboration. Nephrol Dial Transplant 35:1973-1983. https://doi.org/10.1093/ndt/gfaa261

7. Combe C, Kirsch AH, Alfano G et al (2021) At least 156 reasons to prioritize COVID-19 vaccination in patients receiving in-centre haemodialysis. Nephrol Dial Transplant Off Publ Eur Dial Transpl Assoc Eur Ren Assoc 36:571-574. https://doi.org/ 10.1093/ndt/gfab007

8. Munn Z, Peters MDJ, Stern C et al (2018) Systematic review or scoping review? Guidance for authors when choosing between a systematic or scoping review approach. BMC Med Res Methodol. https://doi.org/10.1186/s12874-018-0611-x

9. Tricco AC, Lillie E, Zarin W et al (2016) A scoping review on the conduct and reporting of scoping reviews. BMC Med Res Methodol 16:15

10. Page MJ, McKenzie JE, Bossuyt PM et al (2021) The PRISMA 2020 statement: An updated guideline for reporting systematic reviews. BMJ 372:n71. https://doi.org/10.1136/bmj.n71

11. Alberici F, Delbarba E, Manenti C et al (2020) A report from the Brescia Renal COVID Task Force on the clinical characteristics and short-term outcome of hemodialysis patients with SARSCoV-2 infection. Kidney Int 98:20-26. https://doi.org/10.1016/j. kint.2020.04.030

12. Depetri GC, Brazzoli MA, Puricelli F et al (2020) The peak of the Coronavirus emergency and hemodialysis patients: the experience of the Dialysis Center in Crema. G Ital Nefrol 37(5)

13. Ma Y, Diao B, Lv X et al (2020) Epidemiological, clinical, and immunological features of a cluster of COVID-19-contracted hemodialysis patients. Kidney Int Rep 5:1333-1341. https://doi. org/10.1016/j.ekir.2020.06.003
14. McCafferty K, Davari M, Price K et al (2021) COVID-19 prevalence and seroconversion in an urban hemodialysis unit in the United Kingdom. Hemodial Int 25:137-139. https://doi. org/10.1111/hdi.12883

15. Min Y, Cheng L, Tu C et al (2021) Clinical characteristics of deceased hemodialysis patients affected by COVID-19. Int Urol Nephrol. https://doi.org/10.1007/s11255-020-02700-x

16. Albalate M, Arribas P, Torres E et al (2020) High prevalence of asymptomatic COVID-19 in haemodialysis: learning day by day in the first month of the COVID-19 pandemic. Nefrologia 40:279-286. https://doi.org/10.1016/j.nefroe.2020.06.013

17. Yau K, Muller MP, Lin M et al (2020) COVID-19 outbreak in an urban hemodialysis unit. Am J Kidney Dis 76:690-695.e1. https://doi.org/10.1053/j.ajkd.2020.07.001

18. Xu X, Nie S, Sun J et al (2020) The cumulative rate of SARSCoV-2 infection in chinese hemodialysis patients. Kidney Int Rep 5:1416-1421. https://doi.org/10.1016/j.ekir.2020.07.010

19. Ossareh S, Bagheri SM, Abbasi M et al (2020) Role of screening for COVID-19 in hemodialysis wards, results of a single center study. Iran J Kidney Dis 14:389-398

20. Rodrigo E, Piñera VC, Setién MA et al (2020) Silent COVID19 in haemodialysis facilities in Cantabria, Spain: an ecological study. Clin Kidney J 13:475-476. https://doi.org/10.1093/ ckj/sfaa106

21. Creput C, Fumeron C, Toledano D et al (2020) COVID-19 in patients undergoing hemodialysis: prevalence and asymptomatic screening during a period of high community prevalence in a large paris center. Kidney Med 2:716-723.e1. https://doi. org/10.1016/j.xkme.2020.09.001

22. Canas JJ, Starr MC, Hooks J et al (2021) Longitudinal SARS$\mathrm{CoV}-2$ seroconversion and functional heterogeneity in a pediatric dialysis unit. Kidney Int 99:484-486. https://doi.org/10. 1016/j.kint.2020.11.014

23. Clarke C, Prendecki M, Dhutia A et al (2020) High prevalence of asymptomatic COVID-19 infection in hemodialysis patients detected using serologic screening. J Am Soc Nephrol 31:1969-1975. https://doi.org/10.1681/ASN.2020060827

24. Hains DS, Schwaderer AL, Carroll AE et al (2021) Asymptomatic seroconversion of immunoglobulins to SARS-CoV-2 in a pediatric dialysis unit. JAMA 323:2424-2425. https://doi. org/10.1001/jama.2020.8438

25. Tang H, Tian JB, Dong JW et al (2020) Serologic detection of SARS-CoV-2 infections in hemodialysis centers: a multicenter retrospective study in Wuhan, China. Am J Kidney Dis 76:490499.e1. https://doi.org/10.1053/j.ajkd.2020.06.008

26. Wang R, He H, Liao C et al (2020) Clinical outcomes of hemodialysis patients infected with severe acute respiratory syndrome coronavirus 2 and impact of proactive chest computed tomography scans. Clin Kidney J 13:328-333. https://doi.org/ $10.1093 / \mathrm{ckj} / \mathrm{sfaa} 086$

27. Wang Y, Hu M, Ye G et al (2020) Clinical characteristics of patients with uremia undergoing maintenance hemodialysis complicated with COVID-19. Medicine (Baltimore) 99:e21547. https://doi.org/10.1097/MD.0000000000021547

28. Wang H (2020) Maintenance hemodialysis and COVID-19: saving lives with caution, care, and courage. Kidney Med 2:365-366. https://doi.org/10.1016/j.xkme.2020.03.003

29. Ibernon M, Bueno I, Rodríguez-Farré N et al (2020) The impact of COVID-19 in hemodialysis patients: Experience in a hospital dialysis unit. Hemodial Int Int Symp Home Hemodial 25:205-213. https://doi.org/10.1111/hdi.12905

30. Rodríguez-Espinosa D, Broseta JJJJJJJJJJ, Cuadrado E et al (2020) Prevalence of COVID-19 infection in hemodialysis patients detected using serologic screening. J Am Soc Nephrol JASN 31:2966-2967. https://doi.org/10.1681/ASN.20200 81193 
31. Valga F, Monzón T, Vega-Díaz N et al (2020) SARS-CoV-2 screening in chronic hemodialysis patients in a third-level hospital and its peripheral centers:'one hour less in the Canary Islands'. Nefrol. Publicacion of Soc, Espanola Nefrol

32. Rincon A, Moreso F, Lopez-Herradon A et al (2020) The keys to control a COVID-19 outbreak in a haemodialysis unit. Clin Kidney J 13:542-549. https://doi.org/10.1093/ckj/sfaa119

33. Adapa S, Aeddula NR, Konala VM et al (2020) COVID-19 and renal failure: challenges in the delivery of renal replacement therapy. J Clin Med Res 12:276-285. https://doi.org/10.14740/ jocmr4160

34. Park HC, Kim DH, Yoo KD et al (2020) Korean clinical practice guidelines for preventing transmission of coronavirus disease 2019 (COVID-19) in hemodialysis facilities. Kidney Res Clin Pract 39:145-150. https://doi.org/10.23876/j.krcp.20.046

35. Li J, Xu G (2020) Lessons from the experience in Wuhan to reduce risk of COVID-19 infection in patients undergoing long-term hemodialysis. Clin J Am Soc Nephrol CJASN 15:717-719. https://doi.org/10.2215/CJN.03420320

36. Ulu S, Gungor O, Gok Oguz E et al (2020) COVID-19: a novel menace for the practice of nephrology and how to manage it with minor devastation? Ren Fail 42:710-725. https://doi.org/ 10.1080/0886022X.2020.1797791

37. Shimada N, Shimada H, Itaya Y, Tomino Y (2021) Novel coronavirus disease in patients with end-stage kidney disease. Ther Apher Dial. https://doi.org/10.1111/1744-9987.13599

38. Suri RS, Antonsen JE, Banks CA et al (2020) Management of outpatient hemodialysis during the COVID-19 pandemic: recommendations from the canadian society of nephrology COVID-19 rapid response team. Can J Kidney Health Dis 7:2054358120938564. https://doi.org/10.1177/2054358120 938564

39. Najafi MT, Abbasi MR, Manshadi SAD et al (2020) Surveillance and isolation based strategies to prevent covid-19 in a dialysis center of tehran, a customized approach. Iran J Kidney Dis $14: 321-322$

40. Moura-Neto JA, de Abreu AP, Delfino VDA et al (2020) Good Practice recommendations from the Brazilian society of nephrology to dialysis units concerning the pandemic of the new coronavirus (Covid-19). J Bras Nefrol Orgao Soc Bras E Lat m Nefrol 42:15-17. https://doi.org/10.1590/ 2175-8239-JBN-2020-S105

41. Arenas MD, Villar J, González C et al (2020) Management of the SARS-CoV-2 (COVID-19) coronavirus epidemic in hemodialysis units [Manejo de la epidemia por coronavirus SARSCoV-2 (COVID-19) en unidades de hemodiálisis]. Nefrologia 40:258-264. https://doi.org/10.1016/j.nefroe.2020.04.001

42. Resimont G, Dubois B, Grosch S et al (2020) COVID-19 inside dialysis units [La dialyse chronique face à la COVID-19]. Rev Med Liege 75:41-47

43. Ikizler TA (2020) COVID-19 and dialysis units: what do we know now and what should we do? Am J Kidney Dis 76:1-3

44. Guidance for Infection Control and Prevention of Coronavirus Disease (2019) (COVID-19) in dialysis facilities/CMS. In: Dept. Health Hum. Hum. Serv. https://www.cms.gov/medicarepr ovider-enrollment-and-certificationsurveycertificationgeninfop olicy-and/guidance-infection-control-and-prevention-coronavirus-disease-2019-covid-19-dialysis-facilities

45. Ikizler TA, Kliger AS (2020) Minimizing the risk of COVID-19 among patients on dialysis. Nat Rev Nephrol 16:311-313. https:// doi.org/10.1038/s41581-020-0280-y

46. Prevention II, Settings H (2020) American society of nephrology information for screening and management of COVID-19 in the outpatient dialysis facility release date: March 13, 2020 American Society of Nephrology Information for Screening and Management of COVID-19 in the Outpatient Di. 1-7
47. Basile C, Combe C, Pizzarelli F et al (2020) Recommendations for the prevention, mitigation and containment of the emerging SARS-CoV-2 (COVID-19) pandemic in haemodialysis centres. Nephrol Dial Transplant Off Publ Eur Dial Transpl Assoc Eur Ren Assoc 35:737-741. https://doi.org/10.1093/ndt/gfaa069

48. CDC (2020) Interim additional guidance for infection prevention and control recommendations for patients with suspected or confirmed COVID-19 in outpatient hemodialysis facilitiesICDC. In: CDC. https://www.cdc.gov/coronavirus/2019-ncov/hcp/dialy sis.html. Accessed 25 Apr 2021

49. Meijers B, Messa P, Ronco C (2020) Safeguarding the maintenance hemodialysis patient population during the coronavirus disease 19 pandemic. Blood Purif 49:259-264. https://doi.org/ $10.1159 / 000507537$

50. Verma A, Patel AB, Tio MC, Waikar SS (2020) Caring for dialysis patients in a time of COVID-19. Kidney Med. https://doi.org/ 10.1016/j.xkme.2020.07.006

51. Vega-Vega O, Arvizu-Hernández M, Domínguez-Cherit JG et al (2020) Prevention and control of SARS-CoV-2 (Covid-19) coronavirus infection in hemodialysis units. Salud Publica Mex 62:341-347. https://doi.org/10.21149/11330

52. Kliger AS, Silberzweig J (2020) Mitigating risk of COVID-19 in dialysis facilities. Clin J Am Soc Nephrol CJASN 15:707-709. https://doi.org/10.2215/CJN.03340320

53. Kikuchi K, Nangaku M, Ryuzaki M et al (2020) COVID-19 of dialysis patients in Japan: current status and guidance on preventive measures. Ther Apher Dial 24:361-365. https://doi.org/10. 1111/1744-9987.13531

54. de Abreu AP, Moura Neto JA, Alvares Delfino VD et al (2020) Recommendations from the Brazilian Society of Nephrology regarding the use of cloth face coverings, by chronic kidney patients in dialysis, during the new coronavirus pandemic (Covid-19). J Bras Nefrol 42:9-11. https://doi.org/10.1590/ 2175-8239-JBN-2020-S103

55. Repetto M, Caputo C, Ciabattoni M et al (2020) COVID-19 emergency management at the nephrology and dialysis unit in savona, albenga and cairo montenotte. G Ital Nefrol 37(6)

56. Chandra A, Rao N, Srivastava D (2020) Dialysis in Northern India during COVD-19 pandemic: trying to maintain a balance. Int Urol Nephrol 52:1607-1608. https://doi.org/10.1007/ s11255-020-02524-9

57. Simons T, MacGlashan A, Goldsmith $C$ et al (2021) Initial impact of COVID-19 on dialysis provision; review of international guidelines and adaptation of a hub unit's service. Semin Dial. https://doi.org/10.1111/sdi.12913

58. Tzanno-martins C (2020) Covid-19 pandemic: from carnival masks to surgical masks. J Bras Nefrol Orgao Of Soc Bras E Lat-Am Nefrol 42:361-365. https://doi.org/10.1590/ 2175-8239-JBN-2020-0078

59. de Tavares M, Penido MGMG, de Andrade OVB et al (2020) Recommendations of the Brazilian society of nephrology regarding pediatric patients on renal replacement therapy during the covid19 pandemic. J Bras Nefrol Orgao Soc Bras E Lat-Am Nefrol 42:32-35. https://doi.org/10.1590/2175-8239-JBN-2020-S108

60. Rombolà G, Heidempergher M, Pedrini L et al (2020) Practical indications for the prevention and management of SARS-CoV-2 in ambulatory dialysis patients: lessons from the first phase of the epidemics in Lombardy (Journal of Nephrology, (2020), 33, 2, (193-196), DOI: 10.1007/s40620-020-00727-y). J Nephrol 33:193-196. https://doi.org/10.1007/s40620-020-00727-y

61. Scarpioni R, Manini A, Valsania T et al (2020) Covid-19 and its impact on nephropathic patients: the experience at Ospedale "Guglielmo da Saliceto" in Piacenza. G Ital Nefrol 37(2)

62. Esposito P, Russo R, Conti N et al (2020) Management of COVID-19 in hemodialysis patients: the Genoa experience. Hemodial Int 24:423-427. https://doi.org/10.1111/hdi.12837 
63. Previti A, Lentini P, Di Caprio A et al (2020) The COVID-19 pandemic and hemodialysis: a multicentric experience. G Ital Nefrol 37(6)

64. Lee J-JJ, Lin C-YY, Chiu Y-WW, Hwang S-JJ (2020) Take proactive measures for the pandemic COVID-19 infection in the dialysis facilities. J Formos Med Assoc Taiwan Yi Zhi 119:895-897. https://doi.org/10.1016/j.jfma.2020.03.022

65. Brioni E, Leopaldi D, Magnaghi C et al (2020) Covid-19 in patients on dialysis: infection prevention and control strategies. G Ital Nefrol 37(2)

66. Ippolito M, Di Tria GB, Aldrigo C et al (2020) Standard procedures in dialysis during the Covid-19 epidemic. G Ital Nefrol 37(3)

67. Li SY, Tang YS, Chan YJ et al (2020) Impact of the COVID19 pandemic on the management of patients with end-stage renal disease. J Chin Med Assoc 22:628-633. https://doi.org/ $10.1111 /$ jch. 13912

68. Girndt M (2020) Hygiene in nephrology. Nephrol. https://doi. org/10.1007/s11560-020-00447-1

69. Xiong F, Tang H, Liu L et al (2020) Clinical characteristics of and medical interventions for COVID-19 in hemodialysis patients in Wuhan, China. J Am Soc Nephrol 31:1387-1397. https://doi.org/10.1681/ASN.2020030354

70. Gubensek J, Vajdic Trampuz B, Persic V et al (2020) The possibility of SARS-CoV-2 transmission in a hemodialysis unitreport from a large in-hospital centre. Epidemiol Infect. https:// doi.org/10.1017/S0950268820002277

71. Coffman TM, Chan CM, Choong LH-LL et al (2020) Perspectives on COVID-19 from Singapore: Impact on ESKD care and medical education. J Am Soc Nephrol JASN 31:2242-2245. https://doi.org/10.1681/ASN.2020050721

72. Demirag H, Hintistan S (2020) Coronavirus disease 2019 infection and nursing in patients undergoing hemodialysis treatment. Turk J Nephrol 29:315-321. https://doi.org/10.5152/ turkjnephrol.2020.4397

73. Tang Y, Xin Y, Deng F (2020) Prevention and management of COVID-19 in hemodialysis centers. Am J Manag Care 26:e237-e238. https://doi.org/10.37765/ajmc.2020.43887

74. Weiner DE, Watnick SG (2020) Hemodialysis and COVID-19: an achilles' heel in the pandemic health care response in the United States. Kidney Med 2:227-230

75. Chen G, Zhou Y, Zhang L et al (2020) Core principles for infection prevention in hemodialysis centers during the COVID-19 pandemic. Infect Control Hosp Epidemiol 41:865866. https://doi.org/10.1017/ice.2020.109

76. Vasudevan A, Mantan M, Krishnamurthy S et al (2020) Managing children with renal diseases during the covid-19 pandemic. Indian Pediatr 57:641-651. https://doi.org/10.1007/ s13312-020-1893-8

77. Kant S, Menez SP, Hanouneh M et al (2020) The COVID19 nephrology compendium: AKI, CKD, ESKD and transplantation. BMC Nephrol 21:449. https://doi.org/10.1186/ s12882-020-02112-0

78. Radhakrishnan Y, Hassanein M, Stephany B (2020) Management of COVID-19 in special populations with kidney disease. Cleve Clin J Med. https://doi.org/10.3949/ccjm.87a.ccc067

79. Moura-Neto JA, Palma LMPPMP, Marchiori GF et al (2020) Recommendations from the Brazilian society of nephrology for approaching covid-19 diagnostic testing in dialysis units. J Bras Nefrol Orgao Soc Bras E Lat-Am Nefrol 42:4-8. https:// doi.org/10.1590/2175-8239-JBN-2020-S102

80. Su K, Ma Y, Wang Y et al (2020) How we mitigated and contained the COVID-19 outbreak in a hemodialysis center: lessons and experience. Infect Control Hosp Epidemiol 41:1240 1242. https://doi.org/10.1017/ice.2020.161
81. Burgner A, Ikizler TA, Dwyer JP (2020) Covid-19 and the inpatient dialysis unit managing resources during contingency planning pre-crisis. Clin J Am Soc Nephrol 15:720-722. https://doi. org/10.2215/CJN.03750320

82. Roper T, Kumar N, Lewis-Morris T et al (2020) Delivering dialysis during the COVID-19 outbreak: strategies and outcomes. Kidney Int Rep 5:1090-1094. https://doi.org/10.1016/j.ekir.2020. 05.018

83. Singh T, Ngoh CL, Wong K, Khan BA (2020) Impact of telemedicine on hospitalisation and mortality rates in communitybased haemodialysis centres in singapore during the COVID-19 pandemic. Ann Acad Med Singapore 49:756-763. https://doi. org/10.47102/annals-acadmedsg.2020369

84. Kliger AS, Cozzolino M, Jha V et al (2020) Managing the COVID-19 pandemic: international comparisons in dialysis patients. Kidney Int 98:12-16. https://doi.org/10.1016/j.kint. 2020.04.007

85. Eibensteiner F, Ritschl V, Ariceta G et al (2020) Rapid response in the COVID-19 pandemic: a Delphi study from the European Pediatric Dialysis Working Group. Pediatr Nephrol Berl Ger 35:1669-1678. https://doi.org/10.1007/s00467-020-04584-6

86. Interim SARS-CoV-2 testing guidelines for patients in outpatient hemodialysis facilities/CDC. https://www.cdc.gov/coronavirus/ 2019-ncov/hcp/dialysis/testing-patients.html. Accessed 25 Apr 2021

87. Fadal R, Wadee S, Hoosen A, Parker W (2020) Maximising the efficiency of surveillance for COVID-19 in dialysis units in South Africa: the case for pooled testing. South Afr Med J Suid-Afr Tydskr Vir Geneeskd 110:13039

88. Asim M, Alkadi M, Hamad A et al (2020) Restructuring nephrology services to combat COVID-19 pandemic: report from a Middle Eastern country. World J Nephrol 9:9-17. https://doi.org/ 10.5527/wjn.v9.i2.9

89. Connealy MB, Lew SQ, Alsamman M et al (2021) The emergency department care for hemodialysis patient during the COVID-19 pandemic. Am J Emerg Med 40:47-54. https://doi. org/10.1016/j.ajem.2020.12.006

90. Bell S, Campbell J, McDonald J et al (2020) COVID-19 in patients undergoing chronic kidney replacement therapy and kidney transplant recipients in Scotland: findings and experience from the Scottish renal registry. BMC Nephrol 21:419. https:// doi.org/10.1186/s12882-020-02061-8

91. Watnick S, McNamara E (2020) On the frontline of the COVID19 outbreak: keeping patients on long-term dialysis safe. Clin J Am Soc Nephrol 15:710-713. https://doi.org/10.2215/CJN. 03540320

92. Khoo BZE, See YP, Koh TJK, Yeo SC (2020) Coronavirus disease 2019 (COVID-19) and dialysis: the experience in Singapore. Kidney Med 2:381-384. https://doi.org/10.1016/j.xkme.2020.05. 002

93. Zambrano C, Oliva V, Parenti E et al (2020) Reorganization of haemodialysis during COVID-19 emergency: a report from Dialysis Centers of Parma province. G Ital Nefrol 37(5)

94. Cho J-HH, Kang SH, Park HC et al (2020) Hemodialysis with cohort isolation to prevent secondary transmission during a COVID-19 outbreak in Korea. J Am Soc Nephrol 31:1398-1408. https://doi.org/10.1681/ASN.2020040461

95. Du Y, Feng J, Deng J, et al (2020) Prevention and management of COVID-19 in hemodialysis centers. Doi: https://doi.org/10. 1016/j.ekir.2020.04.001

96. Hu S-C, Fu E-Q, Fan J-F et al (2021) Infection control precautions and care delivery in hemodialysis unit during coronavirus disease 2019 outbreak: a case series. Blood Purif 50:57-64

97. Sipahi S, Dheir H, Tocoglu A, Karabay O (2020) Experience with hemodialysis patients in the COVID-19 pandemic in Sakarya, Turkey. J Coll Phys Surg Pak JCPSP 30:138 
98. Mitchell KR, Bomm A, Shea BS et al (2020) Inpatient dialysis planning during the COVID-19 pandemic: a single-center experience and review of the literature. Int J Nephrol Renov Dis 13:253-259. https://doi.org/10.2147/IJNRD.S275075

99. Tang B, Li S, Xiong Y et al (2020) COVID-19 pneumonia in a hemodialysis patient. Kidney Med 2:354-358. https://doi.org/10. 1016/j.xkme.2020.03.001

100. Dudreuilh C, Kumar N, Moxham V et al (2020) De-isolation of COVID-19-positive hemodialysis patients in the outpatient setting: a single-center experience. Kidney Int 98:236-237

101. Franco RP Recommendations $I R$ ecomendações hemodialysis vascular access maintenance in the Covid-19 pandemic : positioning paper from the Interventional Nephrology Committee of the Brazilian Society of Nephrology 41-43

102. White CA, Kappel JE, Levin A et al (2020) Management of advanced chronic kidney disease during the COVID-19 pandemic: suggestions from the canadian society of nephrology COVID-19 rapid response team. Can J Kidney Health Dis 7:2054358120939354. https://doi.org/10.1177/2054358120 939354

103. Naljayan M, Yazdi F, Struthers S et al (2021) COVID-19 in new orleans: a nephrology clinical and education perspective and lessons learned. Kidney Med. https://doi.org/10.1016/j.xkme.2020. 09.012

104. Critical clarification from CMS: PD catheter and vascular access placement is essential. https://www.kidneynews.org/view/news/ policy-advocacy/leading-edge/critical-clarification-from-cmspd-catheter-and-vascular-access-placement-is-essential.xml. Accessed 25 Apr 2021

105. Yang C-Y, Wang Y-F, Ho Y et al (2020) Hemodialysis vascular access care during the COVID-19 pandemic. J Chin Med Assoc JCMA 83:634-638. https://doi.org/10.1097/JCMA.0000000000 000348

106. Ali LQH (2020) Minimizing the risk of covid-19 in pediatric dialysis center in baghdad/iraq. Indian J Public Health Res Dev 11:323-325. https://doi.org/10.37506/ijphrd.v11i11.11391

107. Shen Q, Wang M, Che R et al (2020) Consensus recommendations for the care of children receiving chronic dialysis in association with the COVID-19 epidemic. Pediatr Nephrol 35:13511357. https://doi.org/10.1007/s00467-020-04555-x

108. Stefan G, Mehedinti AM, Andreiana I et al (2021) Clinical features and outcome of maintenance hemodialysis patients with COVID-19 from a tertiary nephrology care center in Romania. Ren Fail 43:49-57. https://doi.org/10.1080/0886022X.2020. 1853571

109. Zou R, Chen F, Chen D et al (2020) Clinical characteristics and outcome of hemodialysis patients with COVID-19: a large cohort study in a single Chinese center. Ren Fail 42:950-957. https:// doi.org/10.1080/0886022X.2020.1816179

110. Du X, Li H, Dong L et al (2020) Clinical features of hemodialysis patients with COVID-19: a single-center retrospective study on 32 patients. Clin Exp Nephrol 24:829-835. https://doi.org/10. 1007/s10157-020-01904-w

111. Luo Y, Li J, Liu Z et al (2020) Characteristics and outcomes of hemodialysis patients with COVID-19: a retrospective single center study. PeerJ 8:e10459. https://doi.org/10.7717/peerj.10459

112. Tian M, Li H, Yan T et al (2021) Clinical features of patients undergoing hemodialysis with COVID-19. Semin Dial 34:57-65. https://doi.org/10.1111/sdi.12928

113. Trivedi M, Shingada A, Shah M et al (2020) Impact of COVID19 on maintenance haemodialysis patients: the Indian scenario. Nephrology 25:929-932. https://doi.org/10.1111/nep.13760

114. Turgutalp K, Ozturk S, Arici M et al (2021) Determinants of mortality in a large group of hemodialysis patients hospitalized for COVID-19. BMC Nephrol 22:1-10. https://doi.org/10.1186/ s12882-021-02233-0
115. Tayebi Khosroshahi H, Mardomi A, Niknafs B et al (2020) Current status of COVID-19 among hemodialysis patients in the East Azerbaijan Province of Iran. Hemodial Int 25:1-6. https://doi. org/10.1111/hdi.12907

116. Seidel M, Hölzer B, Appel H et al (2020) Impact of renal disease and comorbidities on mortality in hemodialysis patients with COVID-19: a multicenter experience from Germany. J Nephrol 33:8-11. https://doi.org/10.1007/s40620-020-00828-8

117. Savino M, Casula A, Santhakumaran S et al (2020) Sociodemographic features and mortality of individuals on haemodialysis treatment who test positive for SARS-CoV-2: A UK Renal Registry data analysis. PLoS ONE 15:e0241263. https://doi.org/10. 1371/journal.pone. 0241263

118. Mazzoleni L, Ghafari C, Mestrez F et al (2020) COVID-19 outbreak in a hemodialysis center: a retrospective monocentric case series. Can J Kidney Health Dis 7:2054358120944298. https:// doi.org/10.1177/2054358120944298

119. Sánchez-Pérez P, González-Calero P, Poma-Saavedra FH et al (2020) Results of a healthcare organization model for COVID-19 on hemodialysis in a tertiary hospital and its subsidized centers. Nefrologia 40:453-460

120. Silvestri C, Di Stante S, Bertuzzi V et al (2020) SARS CoV-2 related disease features in a population of chronic hemodialysis patients. G Ital Nefrol 37(6)

121. Wu J, Li J, Zhu G et al (2020) Clinical features of maintenance hemodialysis patients with 2019 novel coronavirus-infected pneumonia in Wuhan, China. Clin J Am Soc Nephrol 15:11391145. https://doi.org/10.2215/CJN.04160320

122. Medjeral-Thomas NR, Thomson T, Ashby D et al (2020) Cohort study of outpatient hemodialysis management strategies for COVID-19 in North-West London. Kidney Int Rep 5:2055-2065. https://doi.org/10.1016/j.ekir.2020.08.022

123. Goicoechea M, Sánchez Cámara LA, Macías N et al (2020) COVID-19: clinical course and outcomes of 36 hemodialysis patients in Spain. Kidney Int 98:27-34. https://doi.org/10.1016/j. kint.2020.04.031

124. Zhang J, Cao F, Wu S-KK et al (2020) Clinical characteristics of 31 hemodialysis patients with 2019 novel coronavirus: a retrospective study. Ren Fail 42:726-732. https://doi.org/10.1080/ 0886022X.2020.1796705

125. Aydin Bahat K, Parmaksiz E, Sert S (2020) The clinical characteristics and course of COVID-19 in hemodialysis patients. Hemodial Int 24:534-540. https://doi.org/10.1111/hdi.12861

126. Deshpande R, Dash S, Bahadur MM et al (2020) Study of COVID-19 pandemic in representative dialysis population across Mumbai, India: an observational multicentric analysis. J Assoc Physicians India 68:13-17

127. Pizarro-Sánchez MS, Avello A, Mas-Fontao S et al (2021) Clinical features of asymptomatic SARS-CoV-2 infection in hemodialysis patients. Kidney Blood Press Res. https://doi.org/10.1159/ 000512535

128. Shang W, Li Y, Li H et al (2020) Correlation between laboratory parameters on admission and outcome of COVID-19 in maintenance hemodialysis patients. Int Urol Nephrol 53:165-169. https://doi.org/10.1007/s11255-020-02646-0

129. Hendra H, Vajgel G, Antonelou M et al (2021) Identifying prognostic risk factors for poor outcome following COVID-19 disease among in-centre haemodialysis patients: role of inflammation and frailty. J Nephrol. https://doi.org/10.1007/s40620-020-00960-5

130. Islam M, Ozturk Y, Koc Y (2021) Clinical outcomes of COVID19 in hemodialysis patients in the city of Zonguldak, Turkey. Int Urol Nephrol. https://doi.org/10.1007/s11255-020-02781-8

131. Ozturk S, Turgutalp K, Arici M et al (2020) Mortality analysis of COVID-19 infection in chronic kidney disease, haemodialysis and renal transplant patients compared with patients without kidney disease: a nationwide analysis from Turkey. Nephrol 
Dial Transplant Off Publ Eur Dial Transpl Assoc Eur Ren Assoc 35:2083-2095. https://doi.org/10.1093/ndt/gfaa271

132. Jung H-Y, Lim J-H, Kang SH et al (2020) Outcomes of COVID19 among patients on in-center hemodialysis: an experience from the epicenter in South Korea. J Clin Med 9:1688. https://doi.org/ $10.3390 / \mathrm{jcm} 9061688$

133. Chawki S, Buchard A, Sakhi H et al (2020) Treatment impact on COVID-19 evolution in hemodialysis patients. Kidney Int 98:1053-1054

134. Belavina NI, Frolova NF, Ushakova AI et al (2020) Факторы риска неблагоприятного прогноза у пациентов на программном гемодиализе с Covid-19. Акцент на сердечнососудистую коморбидность Опыт одного центра hemodialysis with Covid-19 . Focus on cardivascular comorbidity. Doi: https:// doi.org/10.28996/2618-9801-2020-Special

135. Petrulewicz A, Rydzewska-Rosołowska A, Fiderkiewicz B et al (2020) The clinical course and short-term outcomes of coronavirus disease 2019 in a cohort of hemodialysis patients. Pol Arch Intern Med 130:809-812. https://doi.org/10.20452/pamw.15479

136. Stock da Cunha T, Gomá-Garcés E, Avello A et al (2020) The spectrum of clinical and serological features of COVID-19 in urban hemodialysis patients. J Clin Med 9:2264. https://doi.org/ 10.3390/jcm9072264

137. De Meester J, De Bacquer D, Naesens M et al (2020) Incidence, characteristics, and outcome of COVID-19 in adults on kidney replacement therapy: a regionwide registry study. J Am Soc Nephrol 32:385-396. https://doi.org/10.1681/ASN.2020060875

138. Shaikh A, Zeldis E, Campbell KN, Chan L (2020) Prolonged SARS-CoV-2 viral RNA shedding and IgG antibody response to SARS-CoV-2 in patients on hemodialysis. Clin J Am Soc Nephrol CJASN 16:290-292. https://doi.org/10.2215/CJN.11120720

139. Otsubo S, Aoyama $Y$ et al (2020) Prolonged shedding ofSARSCoV-2 inCOVID-19 infected hemodialysis patients. Ther Apher Dial. https://doi.org/10.1111/1744-9987.13566

140. Alfano G, Perrone R, Fontana F et al (2020) Long-term effects of COVID-19 in a patient on maintenance dialysis. Hemodial Int Int Symp Home Hemodial 24:E50-E54

141. Rawson A, Wilson AC, Schwaderer AL et al (2020) Coronavirus disease 2019 (COVID-19) in two pediatric patients with kidney disease on chronic immunosuppression: a case series. Hemodial Int 25:E1-E5. https://doi.org/10.1111/hdi.12876

142. Torreggiani M, Ebikili B, Blanchi S, Piccoli GBB (2021) Two episodes of severe acute respiratory syndrome coronavirus 2 infection in a patient on chronic hemodialysis: a note of caution. Kidney Int 99:2020-2021. https://doi.org/10.1016/j.kint.2021. 01.003

143. Asiman I, Latif A, Ansar A et al (2020) How Covid-19 pandemic effects dialysis patients in sialkot district-a cohort study. Pak J Med Health Sci 14:728-730

144. Bigelow BF, Tang O, Toci GR et al (2020) Transmission of SARS-CoV-2 involving residents receiving dialysis in a nursing home-Maryland, April 2020. MMWR Morb Mortal Wkly Rep 69:1089-1094. https://doi.org/10.15585/mmwr.mm6932e4

145. Broseta JJ, Rodríguez-Espinosa D, Cuadrado E et al (2020) SARS-CoV-2 infection in a spanish cohort of CKD-5D patients: prevalence, clinical presentation, outcomes, and de-isolation results. Blood Purif. https://doi.org/10.1159/000510557

146. Espa S (2020) Carta al Director Ictus isquémico asociado a COVID-19 en pacientes en diálisis Ischaemic stroke associated with COVID-19 in dialysis patients. Doi: https://doi.org/10. 1016/j.nefro.2020.07.006

147. La Milia V, Bacchini G, Bigi MC et al (2020) COVID-19 outbreak in a large hemodialysis center in Lombardy, Italy. Kidney Int Rep 5:1095-1099. https://doi.org/10.1016/j.ekir.2020.05.019

148. Quintaliani G, Reboldi G, Di Napoli A et al (2020) Exposure to novel coronavirus in patients on renal replacement therapy during the exponential phase of COVID-19 pandemic: survey of the Italian Society of Nephrology. J Nephrol 33:725-736. https:// doi.org/10.1007/s40620-020-00794-1

149. Schwierzeck V, König JC, Kühn J et al (2021) First reported nosocomial outbreak of severe acute respiratory syndrome coronavirus 2 (SARS-CoV-2) in a pediatric dialysis unit. Clin Infect Dis Off Publ Infect Dis Soc Am 72:265-270. https://doi.org/10. 1093/cid/ciaa491

150. Sim JJ, Huang C-WW, Selevan DC et al (2021) COVID-19 and survival in maintenance dialysis. Kidney Med 3:132-135. https:// doi.org/10.1016/j.xkme.2020.11.005

151. Dominguez-Gil B, Fernandez-Ruiz M et al (2021) Organ donation and transplantation during the COVID-19 pandemic: a summary of the spanish experience. Transplantation 105:29-36. https://doi.org/10.1097/TP.0000000000003528

152. Pio-Abreu A, Nascimento MM, Vieira MA et al (2020) High mortality of CKD patients on hemodialysis with Covid-19 in Brazil. J Nephrol 33:875-877. https://doi.org/10.1007/ s40620-020-00823-z

153. Jager KJ, Kramer A, Chesnaye NC et al (2020) Results from the ERA-EDTA Registry indicate a high mortality due to COVID19 in dialysis patients and kidney transplant recipients across Europe. Kidney Int 98:1540-1548. https://doi.org/10.1016/j.kint. 2020.09.006

154. Keller N, Chantrel F, Krummel T et al (2020) Impact of firstwave COronaVIrus disease 2019 infection in patients on haemoDIALysis in Alsace: the observational COVIDIAL study. Nephrol Dial Transplant 35:1338-1411. https://doi.org/10.1093/ndt/ gfaa170

155. Walker AG, Sibbel S, Wade C et al (2021) SARS-CoV-2 antibody seroprevalence among maintenance dialysis patients in the United States. Kidney Med. https://doi.org/10.1016/j.xkme.2021. 01.002

156. COVID-19 Map-Johns Hopkins Coronavirus Resource Center. https://coronavirus.jhu.edu/map.html. Accessed 18 Apr 2021

157. Discontinuation of transmission-based precautions and disposition of patients with SARS-CoV-2 infection in healthcare settings|CDC. https://www.cdc.gov/coronavirus/2019-ncov/hcp/ disposition-hospitalized-patients.html. Accessed 14 Apr 2021

158. Criteria for releasing COVID-19 patients from isolation. https:// www.who.int/publications/i/item/criteria-for-releasing-covid-19patients-from-isolation. Accessed 14 Apr 2021

159. Pijls BG, Jolani S, Atherley A et al (2021) Demographic risk factors for COVID-19 infection, severity, ICU admission and death: a meta-analysis of 59 studies. BMJ Open. https://doi.org/ 10.1136/bmjopen-2020-044640

160. Novick TK, Rizzolo K, Cervantes L (2020) COVID-19 and kidney disease disparities in the United States. Adv Chronic Kidney Dis 27:427-433

161. Crews DC, Purnell TS (2020) COVID-19, racism, and racial disparities in kidney disease: galvanizing the kidney community response. J Am Soc Nephrol 31

162. Anand S, Montez-Rath M, Han J et al (2020) Prevalence of SARS-CoV-2 antibodies in a large nationwide sample of patients on dialysis in the USA: a cross-sectional study. The Lancet 396:1335-1344. https://doi.org/10.1016/S0140-6736(20)32009-2

163. Bhayani S, Sengupta R, Markossian T et al (2020) Dialysis, COVID-19, poverty, and race in greater Chicago: an ecological analysis. Kidney Med 2:552-558.e1. https://doi.org/10.1016/j. xkme.2020.06.005

Publisher's Note Springer Nature remains neutral with regard to jurisdictional claims in published maps and institutional affiliations. 